\title{
Predictors of Hypertension among Adult Female Population in Kpone-Katamanso District, Ghana
}

\author{
Kwabena Acheampong, ${ }^{1,2}$ Jackim M. Nyamari, ${ }^{2}$ Daniel Ganu, ${ }^{2}$ Stella Appiah, \\ Xiongfeng Pan, ${ }^{1}$ Atipatsa Kaminga, ${ }^{1}$ and Aizhong Liu ${ }^{1}{ }^{1}$ \\ ${ }^{1}$ Department of Epidemiology and Health Statistics, Xiangya School of Public Health, Central South University, \\ Changsha, Hunan 410078, China \\ ${ }^{2}$ Department of Public Health, Adventist University of Africa, Nairobi 00503, Kenya \\ ${ }^{3}$ Department of Nursing, Valley View University, Accra 00233, Ghana \\ Correspondence should be addressed to Aizhong Liu; lazroy@live.cn
}

Received 19 December 2018; Revised 26 April 2019; Accepted 28 May 2019; Published 11 June 2019

Academic Editor: Tomohiro Katsuya

\begin{abstract}
Copyright (C) 2019 Kwabena Acheampong et al. This is an open access article distributed under the Creative Commons Attribution License, which permits unrestricted use, distribution, and reproduction in any medium, provided the original work is properly cited.
\end{abstract}

\begin{abstract}
Background. Hypertension is an independent risk factor of cardiovascular disease, which is one of the biggest health challenges today. The objective of this study was to estimate the prevalence of the problem and other factors related to hypertension among women who are 25 years and above. Methods. A community-based cross-sectional study was conducted from September and November 2017. A multistage cluster sampling technique was used to select the study participants. The data was collected using a structured questionnaire and physical measurements adapted from "WHO STEPwise approach to chronic disease risk factor surveillance (STEPS)." Data were examined using the SPSS program IBM version 20. Descriptive statistics, including proportions, frequencies, and cross-tabulations, were used to summarize the study variables. A binary logistic regression was fitted variable with a $p$ value of $<0.7$. The bivariable analyses were entered in the multivariable analysis to control the possible effect of confounders. Multivariable logistic regression analysis was used to identify factors associated with hypertension. The Adjusted Odds Ratio (AOR) with a $95 \%$ Confidence Interval (CI) was computed to show the level of certainty. A $p$ value of $<0.05$ was considered statistically significant. Results. The study indicated that the prevalence of hypertension (BP $\geq 140 / 90 \mathrm{mmHg}$ ) was 33.8\% (95\% CI 27.4-40.2) which increased with age. At the time of the study, women aged 45-64 years [AOR $=2.19$, (95\% CI: 1.11-4.34, p<0.02)] and 65+ years $[\mathrm{AOR}=5.13$, (95\% CI: 2.20-11.99), $\mathrm{p}<0.001]$ were two to five times as likely as those with age of 25-44 years to be hypertensive. Women who had a higher body mass index $(\mathrm{BMI}) \geq 30 \mathrm{~kg} / \mathrm{m}^{2}$ were two times as likely as those with normal weight to be hypertensive [AOR 2.38, (95\% CI; 1.14-4.95, p<0.02)]. Women who did not consume fresh fruit daily were three times as likely as those women who consume fresh fruit daily to be hypertensive [AOR 3.17 (95\% CI; 1.05-9.55, p<0.04)]. Conclusion. Increasing age, obesity, and women who did not consume fresh fruits daily were associated with hypertension, indicating opportunities for health education and other prevention measures.
\end{abstract}

\section{Introduction}

Cardiovascular disease is the top cause of death in women in every major developed country and most emerging economies [1]. It involves the heart or blood vessels which affect about 1.1 billion people worldwide, maintains the top independent contributor to the global burden of disease, and accounts for 17.9 million deaths annually [2].

Hypertension is a risk factor for cardiovascular disease [3], and the complications of uncontrolled hypertension include stroke, heart failure, coronary heart diseases, peripheral vascular disease, retinal hemorrhage, visual impairment, and renal impairment [4-7]. Its early detection, prevention, prompt treatment, and control in sub-Saharan Africa (SSA) are suboptimal [8]. This is due to a combination of lack of resources and health-care systems, barriers to absolute compliance with prescribed medications or drugs, lack of effective preventive strategies at a population level, and lack of sustainable drug therapy. 
The economic or fiscal impact for a number of years lost due to ill-health or early death and the need to divert scarce resources to tertiary care are substantial. The adult people with hypertension in 2000 were 972 million and were estimated to increase by $60 \%$ to a total of 1.56 billion in 2025 [9]. The rise in its prevalence will occur largely in developing countries [10].

Although the number of people with hypertension in developed countries was projected to increase by $24 \%$ from 333 million to 413 million, an increase of $80 \%$ was projected for developing countries from 639 million to 1.15 billion. This alarming increase in hypertension projected by a previous study [10] portrays a serious problem for SSA countries. Collectively, previous population-based studies have shown that hypertension in Ghana is a common problem and is reported to be as high as 19-48 \% [11-14].

Nevertheless, some district in Ghana still lacks crosssectional data on the prevalence of hypertension, its risk factors, and how this is distributed. The objective of the study was to estimate the prevalence of the problem and other factors related to hypertension among women who are 25 years and above in the district.

\section{Materials and Methods}

2.1. Study Design. A cross-sectional study was conducted to determine the factors of hypertension among the adult female population in Kpone-Katamanso District, located in the Greater Accra region of Ghana. Data collection started in September and ended in November 2017.

2.2. Sampling Size and Method. The sample size was calculated on the basis of a previous study which recorded the prevalence of hypertension in population as $19 \%$ or higher $[14,15]$ and error of margin as $5 \%$ with $95 \%$ confidence interval. The minimum sample size required for 25406 female populations was calculated as $\mathrm{n}=234$ participants. Since the sampling procedure was multistage and taking into consideration the design effect, the sample size was further increased by 1.2 times and nonresponse rate by $7 \%$. The total calculated sample size was 300 participants (derived by EpiInfo software version 7).

Multistage cluster sampling was employed for this study, which involved selecting communities and households. This study used a minimum number of the cluster by randomly choosing 4 communities from a list of 19 communities from the district. The basic sampling units in selected clusters were households. With a required sample size of 300 and one cluster(s) (representing four communities), the minimum sample required for each community was 37.5 households. Systematic sampling method was used to select the needed number of households in the cluster which applies to all the 4 selected communities. A total number of households in the district were 26,800 with an average household size of 4.1. However, the estimated number of households for the selected cluster was 5640 . The interval for the cluster was then calculated by dividing the estimated number of households by the number of sample size (300) which gave an interval of 19th. A number within the sampling interval was randomly selected to get the first household to visit which was 4 th. Consequently, households to visit were identified by adding up the sampling interval to the number selected. This was done until the 37.5 households required from each community making 150 households from a cluster were obtained. In households with more than two eligible persons, two were selected for the study using simple random sampling technique. In the nonappearance or absence of eligible persons in a selected household, at the time of the survey, the adjacent household was selected as shown in the above (Figure 1). A total of 216 adults consented and participated in the house survey, yielding a response rate of $72.0 \%$.

2.3. Inclusion and Exclusion Criteria. Women aged 25 and above years in the selected study area who were permanent residents in the target area and who have been living there at least for six months were considered eligible for the study regardless of their status of blood pressure, while women who are unable to give response due to mental illness and those who were pregnant were excluded from the study.

2.4. Variables Measurement and Definition. Current Smoker was defined as a participant who reported smoking or any tobacco product within the last 30 days. Current Alcohol Drinker was defined as a participant who consumed alcohol within the last 30 days. Extra intake of salt was defined as participants who added a quantity of salt to food before consumption in addition to the usual amount added to food during cooking. Exercise is a planned physical activity that leads to visible improvements in health and general wellbeing. Hence physical exercise was defined as participants who engaged any vigorous or moderate exercise ranging from cardio exercises, running, brisk walking, skipping, weight lifting, and others, for a day or for most of the days in a week excluding manual workers like laborers, farmers, fishermen, and other manual workers. The fruit was characterized by daily intake of pawpaw, mango, grapes, watermelon, pears, strawberries, oranges, apples, pineapple, etc., and this was exclusively limited to fresh fruits.

2.4.1. Dependent Variable. Women with systolic blood pressure $\geq 140 \mathrm{mmHg}$ and diastolic blood pressure $\geq 90 \mathrm{mmHg}$ or both were categorized as being hypertensive. The Joint National Committee 7 report released in 2003 categorizes blood pressure as follows: normal blood pressure (systolic $(\mathrm{SBP}) /$ diastolic $(\mathrm{DBP})<120 / 80 \mathrm{mmHg}$ ); prehypertension (SBP 120-139 mmHg or DBP $80-89 \mathrm{mmHg}$ ); stage 1 hypertension (SBP 140-159 $\mathrm{mmHg}$ or DBP 90-99 $\mathrm{mmHg}$ ); and stage 2 hypertension ( $\mathrm{SBP} \geq 160 \mathrm{mmHg}$ or $\mathrm{DBP} \geq 100 \mathrm{mmHg}$ ) [16].

2.4.2. Independent Variables. The sociodemographic characteristics are like age, marital status education status, employment status, and religion. Behavioral factors are like smoking, alcohol consumption, extra salt intake, daily fruit intake, fast and fried foods intake, and physical exercise and obesity. 


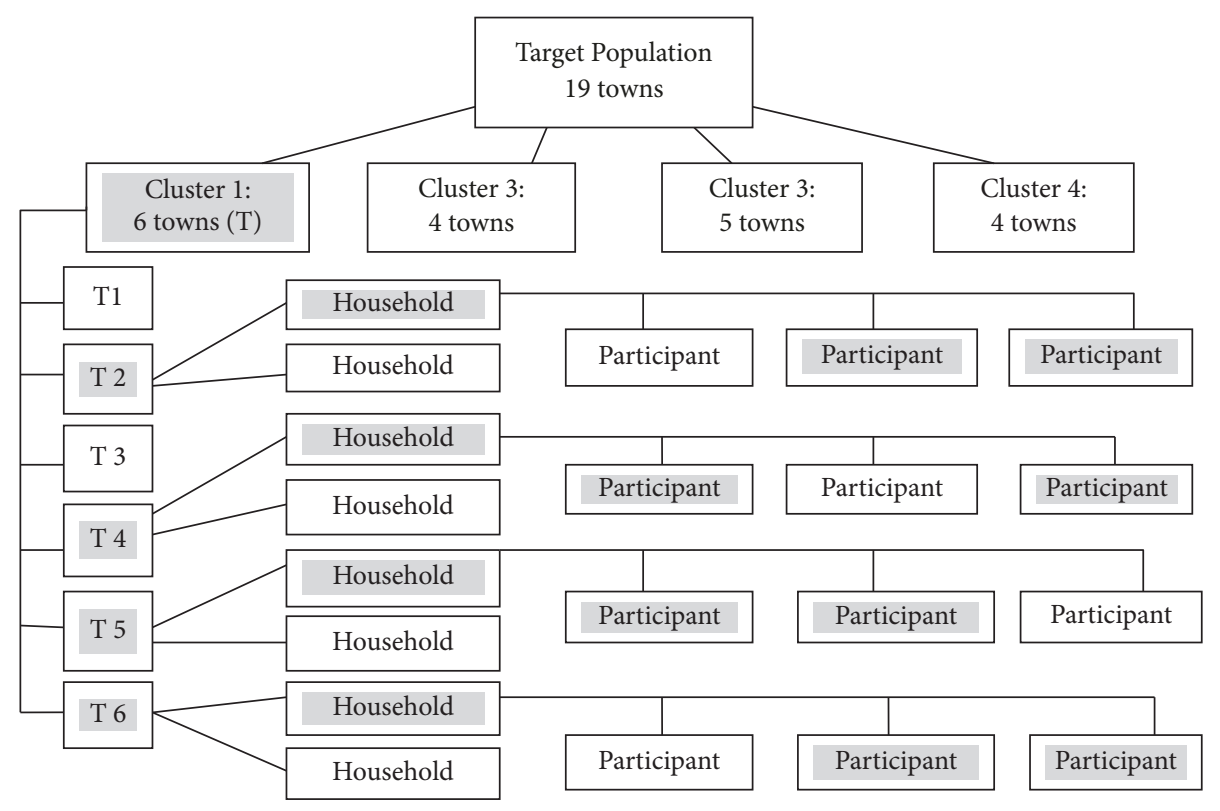

FIGURE 1: Flow chart of the sampling method. ${ }^{\mathrm{a}}$ Town $(\mathrm{T})$ or community represents a smaller cluster selected from the bigger cluster. ${ }^{\mathrm{b}}$ A grey box shows that the box was selected to be sampled.

2.5. Blood Pressure Measurements. The blood pressure measurements were taken using aneroid sphygmomanometer and stethoscope (pM-A01S). Period of rest before the BP was taken is variously given as " 5 minutes" and "at least 5 to 10 minutes of rest." The average of two systolic and diastolic blood pressure measurements was calculated and used as a dependent variable in the analysis. Hypertensive subjects were defined as those with systolic blood pressure (SBP) $\geq 140$ $\mathrm{mmHg}$ and/or diastolic blood pressure (DBP) $\geq 90 \mathrm{mmHg}$ or being previously diagnosed as hypertensive by any health professional.

2.6. Anthropometric Measurement. Weight was measured to the nearest $0.1 \mathrm{~kg}$ using bathroom scale with shoes off. It was validated with standard pressure and corrected for zero inaccuracy. Height was measured without shoes to the closest $0.5 \mathrm{~cm}$ using stadiometer. The BMI was computed as weight in kilograms divided by the square of the height in meters. BMI of participants were categorized as underweight $(<18.5$ $\mathrm{kg} / \mathrm{m}^{2}$ ), normal weight (BMI $\leq 18.5$ to $24.9 \mathrm{~kg} / \mathrm{m}^{2}$ ), overweight $\left(\geq 25\right.$ to $\left.29.9 \mathrm{~kg} / \mathrm{m}^{2}\right)$, and obese $\left(\mathrm{BMI} \geq 30 \mathrm{~kg} / \mathrm{m}^{2}\right)$ [17].

2.7. Data Collection and Management. Participants were interviewed using a structured questionnaire consisting of sociodemographic features, behavioral factors, and physical measurements adapted from "WHO STEPwise approach to chronic disease risk factor surveillance (STEPS)." The data collectors were four community health nurses supervised by two research officers. Training and practical demonstrations on the interview techniques and measurement procedures were given to data collectors for three consecutive days. Data reviewers were stationed at each town to ensure completeness of data recording by the field workers. Data collected was then entered into a safe computerized database using a unique code to ensure data accuracy.

2.8. Data Processing and Analysis. Data were coded and examined using the SPSS program IBM version 20. Descriptive statistics, including cross-tabulations, proportions, and frequencies, were used to recap the study variables. We performed an exploratory analysis using the Pearson Chi-square test $(\chi 2)$. The association between hypertension and the independent variables was investigated by using the binary logistic regression and $p$ values of $<0.7$ were considered as a variable selection criterion. Variables with a $p$ value less than 0.7 were entered in the multivariable analysis to control the potential effect of confounders. Multivariable regression analysis was used to determine factors associated with the prevalence of hypertension. The Adjusted Odds Ratio (AOR) with a $95 \%$ Confidence Interval (CI) was computed to show the level of certainty. A $p$ value of $<0.05$ was considered as statistically significant.

2.9. Ethics Approval. Administrative permission was granted from the Kpone-Katamanso District Health Management Team. The participants were well informed about the study, its objectives, and method of data collection. Participants who agreed to be part of the survey gave their consent before being interviewed. The questionnaires were reviewed by the Valley View University and Adventist University of Africa Campus Institutional Research Ethics Review Committee.

\section{Results}

3.1. Background Characteristics of the Study Subjects. Two hundred and sixteen (with a response rate of $72.0 \%$ ) 
participants were included in this study with the mean age of $49.6 \pm 13.3$ years. Slightly more than two-thirds of the participants had no formal education: 100 (46.3\%). More than one-third were not married and the majority of them were not employed: 84 (39.0\%). The average weight of the study participants was $71.9 \pm 17.2 \mathrm{~kg}$, height was $160.4 \pm 5.5 \mathrm{~cm}$, and BMI was $27.9 \pm 6.3 \mathrm{~kg} / \mathrm{m}^{2}$. Out of 216 participants, $76(35.2 \%)$ had normal weight, 4 (1.9\%) were underweight, $70(32.2 \%)$ were overweight, and $70(32.2 \%)$ were obese (Table 1$)$.

3.2. Prevalence of Hypertension. Blood pressure measurements were done to all the study subjects to check for hypertension. The mean systolic and diastolic blood pressure results were (Mean \pm SD) $125.7 \pm 18.4 \mathrm{mmHg}$ and $79.7 \pm 12.7 \mathrm{mmHg}$, respectively. Out of 216 participants included, 73 (33.8\%) of them were hypertensive, of which 26 $(36.0 \%)$ are previously diagnosed as having the condition and $47(64.0 \%)$ were newly diagnosed as hypertension.

\subsection{Prevalence of Hypertension by Sociodemographic Charac-} teristics. Prevalence hypertension was high among participants with age group of 65 years and above $(57.0 \%)$ as compared to those with a low age group of 25-44 years $(21.0 \%)$. The proportion of hypertension depicted an increasing trend with age. A statistically significant difference $(p<0.001)$ was found between age and prevalence of hypertension. However, marital status education, employment, and religion were not statistically significant as summarized in Table 2.

\subsection{Prevalence of Hypertension by Lifestyle-Related Factors.} Prevalence of hypertension by lifestyle-related factors among study participants is summarized in Table 3 . The prevalence of hypertension was higher among women who did not consume fresh fruits daily $68(37 \%)$ than those who did $5(17 \%)$ and the difference was significant $(\mathrm{p}<0.03)$. Although the proportion of hypertension was high among participants who reported to have added extra salt in their food after cooking, $56(35.0 \%)$, as compared with those who did not, 17(31.0\%), it was not statistically significant $(\mathrm{p}>0.60)$. A statistically significant difference $(\mathrm{p}<0.02)$ was found between BMI and the prevalence of hypertension.

3.5. Factors Associated with the Prevalence of Hypertension. Factors associated with the prevalence of hypertension among study participants are summarized in Table 4. Beyond the bivariate analysis of this study, the multivariable logistic regression analysis was computed. On bivariate analysis, a participant who consumes alcohol was about two times as likely as those who did not consume alcohol to be hypertensive and the crude odds ratio (COR) is 1.6 [95\% CI (0.87-2.98)]. Participants who did not have formal education were about two times as likely as those who have attained higher education to be hypertensive [COR 1.76 (95\% CI; 0.535.86)].

The multivariate analysis showed the estimates of the association between independent variables and the prevalence of hypertension. After adjustment for age, marital status, education status, employment status, alcohol drinking,
TABLE 1: The background characteristics of the study subjects $(\mathrm{n}=216)$.

\begin{tabular}{|c|c|}
\hline Variables & Frequency (\%) \\
\hline \multicolumn{2}{|l|}{ Age in years } \\
\hline $25-44$ & $97(45.0)$ \\
\hline $45-64$ & $82(38.0)$ \\
\hline $65+$ & $37(17.0)$ \\
\hline \multicolumn{2}{|l|}{ Marital Status } \\
\hline No & $69(32.0)$ \\
\hline Yes & $147(68.0)$ \\
\hline \multicolumn{2}{|l|}{ Level of Education } \\
\hline None & $100(46.3)$ \\
\hline Primary & $52(24.1)$ \\
\hline Secondary & $48(22.2)$ \\
\hline Tertiary & $16(7.4)$ \\
\hline \multicolumn{2}{|l|}{ Employment Status } \\
\hline Employed & $132(61.0)$ \\
\hline Unemployed & $84(39.0)$ \\
\hline \multicolumn{2}{|l|}{ Religion } \\
\hline Islam & $6(3.0)$ \\
\hline Christianity & $210(97.0)$ \\
\hline \multicolumn{2}{|l|}{ Blood Pressure } \\
\hline Normal & $126(58.3)$ \\
\hline Prehypertension & $17(7.9)$ \\
\hline Stage 1 hypertension & $59(27.3)$ \\
\hline Stage 2 hypertension & $14(6.5)$ \\
\hline \multicolumn{2}{|l|}{ BMI $(\mathrm{kg} / \mathrm{m} 2)$} \\
\hline Underweight & $4(1.9)$ \\
\hline Normal & $72(33.3)$ \\
\hline Overweight & $70(32.4)$ \\
\hline Obese & $70(32.4)$ \\
\hline
\end{tabular}

extra salt intake, fast foods intake, and body mass index, the participants who were 45-64 years [AOR $=2.19,(95 \%$ CI: $1.11-4.34, \mathrm{p}<0.02)]$ and $65+$ years $[\mathrm{AOR}=5.13,(95 \% \mathrm{CI}$ : $2.20-11.99), \mathrm{p}<0.001]$ were two to five times as likely as those with age of 25-44 years to be hypertensive. Participants who were obese were two times as likely as those who have normal weight [AOR 2.38, (95\% CI; 1.14-4.95, p<0.02)]. Participants who do not consume daily fresh fruit were about 3 times [AOR 3.17 (95\% CI; 1.05-9.55, p<0.04)] as likely as those who consume daily fresh fruit to be hypertensive. No significant association was observed between the prevalence of hypertension and marital status or education status or employment status or alcohol drinking or extra salt intake or fast foods intake or physical exercise.

\section{Discussion}

The prevalence of hypertension (33.8\% [95\% CI 27.4-40.2]) established in this study corresponds to the findings of Addo et al. [11] and Burket [12], who reported that the prevalence of hypertension among women in Ghana was $30.2 \%$ and $30.7 \%$, respectively. However, the prevalence found in our study is 
TABle 2: Prevalence of hypertension by sociodemographic characteristics.

\begin{tabular}{|c|c|c|c|c|}
\hline Variables & $\begin{array}{c}\text { Normal (\%) } \\
(\mathrm{n}=143)\end{array}$ & $\begin{array}{c}\text { Hypertensive (\%) } \\
(\mathrm{n}=73)\end{array}$ & $\begin{array}{c}\text { Total }(\%) \\
(\mathrm{n}=216)\end{array}$ & $P$ value \\
\hline Age & & & & $<0.001$ \\
\hline $25-44$ & $77(79.0)$ & $20(21.0)$ & $97(44.9)$ & \\
\hline $45-64$ & $50(61.0)$ & $32(39.0)$ & $82(38.0)$ & \\
\hline $65+$ & $16(43.0)$ & $21(57.0)$ & $37(17.1)$ & \\
\hline Marital Status & & & & 0.256 \\
\hline No & $42(61.0)$ & $27(39.0)$ & $69(31.9)$ & \\
\hline Yes & $101(69.0)$ & $46(31.0)$ & $147(68.1)$ & \\
\hline Level of Education & & & & 0.685 \\
\hline No formal Education & $63(63.0)$ & $37(37.0)$ & $100(46.3)$ & \\
\hline Primary & $34(65.0)$ & $18(35.0)$ & $52(24.1)$ & \\
\hline Secondary & $34(71.0)$ & $14(29.0)$ & $48(22.2)$ & \\
\hline Tertiary & $12(75.0)$ & $4(25.0)$ & $16(7.4)$ & \\
\hline Employment Status & & & & 0.441 \\
\hline Employed & $90(68.0)$ & $42(32.0)$ & $132(61.1)$ & \\
\hline Unemployed & $53(63.0)$ & $31(37.0)$ & $84(38.9)$ & \\
\hline Religious Status & & & & 0.368 \\
\hline Islam & $5(83)$ & $1(17.0)$ & $6(2.8)$ & \\
\hline Christianity & $138(66)$ & $72(34.0)$ & $210(97.2)$ & \\
\hline
\end{tabular}

TABLe 3: Prevalence of hypertension by lifestyle and comorbidities factors.

\begin{tabular}{|c|c|c|c|c|}
\hline Variables & $\begin{array}{c}\text { Normal (\%) } \\
(n=143)\end{array}$ & $\begin{array}{c}\text { Hypertension }(\%) \\
(\mathrm{n}=73)\end{array}$ & $\begin{array}{c}\text { Total }(\%) \\
(n=216)\end{array}$ & $\mathrm{p}$ value \\
\hline Smoking Status & & & & 0.77 \\
\hline No & $138(66.0)$ & $71(97.3)$ & $209(96.8)$ & \\
\hline Yes & $5(71.0)$ & $2(29.0)$ & $7(3.2)$ & \\
\hline Alcohol status & & & & 0.13 \\
\hline No & $108(69.0)$ & $48(31.0)$ & $156(72.2)$ & \\
\hline Yes & $35(58.0)$ & $25(42.0)$ & $60(27.8)$ & \\
\hline Extra salt intake & & & & 0.60 \\
\hline No & $38(69.0)$ & $17(31.0)$ & $55(25.5)$ & \\
\hline Yes & $105(65.0)$ & $56(35)$ & $161(74.5)$ & \\
\hline Physical Exercise & & & & 0.83 \\
\hline No & $98(67)$ & $49(33)$ & $147(68.1)$ & \\
\hline Yes & $45(65)$ & $24(35)$ & $69(31.9)$ & \\
\hline Daily Fresh Fruit Intake & & & & $<0.03$ \\
\hline No (Absence) & $118(63)$ & $68(37)$ & $186(86.1)$ & \\
\hline Yes & $25(83.0)$ & $5(17)$ & $30(13.9)$ & \\
\hline Fast \& Fried Foods & & & & 0.12 \\
\hline No & $93(63)$ & $55(37)$ & $148(68.5)$ & \\
\hline Yes & $50(74)$ & $18(26.0)$ & $68(31.5)$ & \\
\hline BMI, $\mathrm{kg} / \mathrm{m}^{2}$ & & & & $<0.02$ \\
\hline Underweight & $4(100)$ & $0(0.0)$ & $4(1.9)$ & \\
\hline Normal & $55(71.0)$ & $21(29.0)$ & $72(33.3)$ & \\
\hline Overweight & $52(74)$ & $18(26.0)$ & $70(32.4)$ & \\
\hline Obesity & $36(51.0)$ & $34(49)$ & $70(32.4)$ & \\
\hline
\end{tabular}


TABLE 4: Binary and multivariable logistic regression analysis between predictor variables and hypertension among people living in KponeKatamanso District, Accra, Ghana.

\begin{tabular}{|c|c|c|c|c|}
\hline \multirow{2}{*}{ Variables } & \multicolumn{4}{|c|}{ Hypertension } \\
\hline & COR $(95 \% \mathrm{CI})$ & Pvalue & $\operatorname{AOR}(95 \% C I))$ & $P$ value \\
\hline Age years & & $<0.001$ & & \\
\hline $25-44$ & 1 & - & 1 & \\
\hline $45-64$ & $2.46[1.27-4.78]$ & $<0.010$ & $2.19[1.11-4.34]$ & $<0.020$ \\
\hline $65+$ & $5.05[2.24-11.42]$ & $<0.001$ & $5.13[2.20-11.99]$ & $<0.001$ \\
\hline Marital status (Ref: Yes) & 1 & - & 1 & - \\
\hline Single & $1.41[0.78-2.56]$ & 0.257 & $1.42[0.70-2.86]$ & 0.322 \\
\hline $\begin{array}{l}\text { Education status (Ref: } \\
\text { Tertiary) }\end{array}$ & 1 & - & 1 & - \\
\hline No formal Education & $1.76[0.53-5.86]$ & 0.356 & $1.79[0.48-6.70]$ & 0.389 \\
\hline Primary \& Below & $1.59[0.45-5.64]$ & 0.474 & $1.23[0.31-4.92]$ & 0.769 \\
\hline Secondary School & $1.24[0.34-4.49]$ & 0.748 & $1.13[0.28-4.60]$ & 0.867 \\
\hline $\begin{array}{l}\text { Employment status (Ref: } \\
\text { No) }\end{array}$ & 1 & - & 1 & - \\
\hline Unemployed & $1.25[0.71-2.23]$ & 0.441 & $1.59[0.809-3.111]$ & 0.179 \\
\hline Smoking (Ref: No) & 1 & - & & \\
\hline Current Smoking & $0.78[0.15-4.11]$ & 0.767 & & \\
\hline Alcohol (Ref: No) & 1 & - & 1 & - \\
\hline Alcohol drinking & $1.60[0.87-2.98]$ & 0.129 & $1.55[0.766-3.143]$ & 0.223 \\
\hline Extra Salt Intake (Ref: No) & 1 & - & 1 & - \\
\hline Extra Salt Intake & $1.19[0.62-2.30]$ & 0.600 & $\begin{array}{c}1.34 \\
{[0.635-2.808]}\end{array}$ & 0.446 \\
\hline $\begin{array}{l}\text { Daily Fresh Fruit Intake } \\
\text { (Ref: Yes) }\end{array}$ & 1 & - & 1 & - \\
\hline No Daily Fruit Intake & $2.88[1.05-7.88]$ & $<\mathbf{0 . 0 3 9}$ & $3.17[1.05-9.55]$ & $<0.040$ \\
\hline Fast Foods Intake (Ref: no) & $0.61[0.32-1.15]$ & 0.125 & $0.69[0.33-1.45]$ & 0.331 \\
\hline Physical Exercise (Ref: yes) & 1 & - & & \\
\hline No Physical Exercise & $0.94[0.51-1.71]$ & 0.834 & & \\
\hline \multicolumn{5}{|l|}{ BMI, $\mathrm{kg} / \mathrm{m}^{2}$} \\
\hline BMI, kg/m² (Ref: <25) & 1 & - & 1 & \\
\hline BMI $(\geq 25,<30) \mathrm{kg} / \mathrm{m}^{2}$ & $0.91[0.44-1.89]$ & 0.794 & $0.93[0.43-2.00]$ & 0.840 \\
\hline BMI, $(\geq 30) \mathrm{kg} / \mathrm{m}^{2}$ & $2.47[1.24-4.92]$ & $<0.010$ & $2.38[1.14-4.95]$ & $<\mathbf{0 . 0 2 0}$ \\
\hline
\end{tabular}

shown to be higher than the $25.5 \%$ reported for women in South West Nigeria rural communities [18] and the $15.0 \%$ reported for Eritrea national blood pressure survey [19], but lower than $48 \%$ prevalence reported among women in Accra by Hill et al. [13]. This change may be elucidated by differences in study location, sample size, and the average age of the study participants.

Age has been recognized as a nonmodifiable risk factor, attributing to an increased risk of cardiovascular problems, such as hypertension [20-23]. The present study is consistent with previous studies suggesting an association between increasing age and hypertension [24, 25]. One potential reason could be that vascular resistance increases with age when the vascular wall becomes harder. This change combined with age-linked conditions such as chronic heart failure which reduce cardiac output results in the increased incidence of hypertension among older age [26]. Therefore, increase of life expectancy among women in Ghana necessitates a practical and effective hypertension management strategy that targets its aging population.

Obesity and hypertension risks have been reported by previous studies [27-30], which support our finding. Similar results were observed in various studies done by Shihab et al. [31] and Tibazarwa et al. [32] which reported the occurrence of increasing body mass index and its significant impact on the development of hypertension. A study was done by Adedoyin et al. also reported a positive association with BMI and hypertension [33]. For that reason, the commencement of weight trimming program is required and would be more useful for young adults or middle-aged populations, to prevent the development of hypertension.

Our finding suggested that women who did not consume fresh fruit daily were found to be associated with the prevalence of hypertension. Borghi et al., Mirmiran et al., and $\mathrm{Wu}$ 
et al. provided evidence that fruit intake is associated with a lower risk of hypertension [34-36]. Other studies conducted among 28,082 female health professionals in the United States and a prospective cohort study among 745 residents aged 35 years without home hypertension at baseline from Ohasama, Japan, also reported a relationship between fruit consumption and decreased risk of hypertension [37, 38]. Lately, a longitudinal study conducted in China affirms that fruit intake was more robustly and significantly associated with lowering blood pressure than vegetable intake [39]. However, Nunez-Cordoba et al. reported no association between fruit intake and risk of hypertension [40], which needs to be researched further. The incidence of low daily fresh fruit intake and risk of hypertension in this study offers proof and support for the long-term education on the significance of fresh fruit intake and the prevention of hypertension.

Contrary to other studies, this study did not find any significant relationship between low education, unemployment, smoking, alcohol consumption, lack of physical exercise, and excessive salt intake which are significantly associated with hypertension in these studies [41-44].

\section{Limitation of the Study}

There are several limitations in this study. First, the study is cross-sectional which does not infer causal relationships. Besides, we took samples from only four towns and therefore caution should be taken to generalize the data for the entire population. Second, the determination of blood pressure was based on a single-day measurement instead of 24-hour ambulatory blood pressure, although two readings were taken. This strategy or approach might lead to misclassification of blood pressure category and introduce dilution bias, possibly underestimated or overestimated prevalence. Third, the proportion of the enrolled sample aged 65 years is higher than would be expected in the general population in the Greater Accra Region. This might lead to an oversampling of this age group. Fourth, the participation rate of this study was $72 \%$, which is acceptable. However, the participation rate of $100 \%$ at recruitment is more confident and generalizable. Fifth, age of 65 years and above was assessed via open-ended strata, which may introduce some degree of residual confounding and selection bias. Again, despite comprehensive adjustment for multiple lifestyles and dietary factors, residual confounding by unmeasured or imprecisely measured hypertension risk factors may persist. Sixth, there was no census of the number of households in each town. However, secondary data from the 2010 Population and Housing Census was used, which might lead to underestimation of the true number of households.

\section{Conclusion}

The prevalence of hypertension was found to be high among women in the Kpone-Katamanso District. Older age, obesity, and women who did not consume fresh fruits daily were found to be significantly associated with hypertension. We recommend that for prevention of hypertension addressing no fruit intake and encouraging physical activity should be the primary option.

\section{Data Availability}

The data used to support the findings of this study are available from the corresponding author upon request.

\section{Conflicts of Interest}

The authors declare that they have no conflicts of interest.

\section{References}

[1] L. Gholizadeh and P. Davidson, "More similarities than differences: An international comparison of CVD mortality and risk factors in women," Health Care for Women International, vol. 29, no. 1, pp. 3-22, 2008.

[2] World Health Organization, Cardiovascular Disease, World Health Organization, Geneva, Switzerland, 2016, https://www .who.int/cardiovascular_diseases/en/.

[3] A. Reed, R. Suri, and R. Marcovich, "Passage of embolization coil through urinary collecting system one year after embolization," Urology, vol. 70, no. 6, pp. 1222.e17-1222.e18, 2007.

[4] C. M. Lawes, S. V. Hoorn, and A. Rodgers, "Global burden of blood-pressure-related disease, 2001," The Lancet, vol. 371, no. 9623, pp. 1513-1518, 2008.

[5] F. Pistoia, S. Sacco, D. Degan, C. Tiseo, R. Ornello, and A. Carolei, "Hypertension and stroke: epidemiological aspects and clinical evaluation," High Blood Pressure \& Cardiovascular Prevention, vol. 23, no. 1, pp. 9-18, 2016.

[6] S. Wu, Z. Huang, X. Yang et al., "Cardiovascular events in a prehypertensive Chinese population: four-year follow-up study," International Journal of Cardiology, vol. 167, no. 5, pp. 2196-2199, 2013.

[7] Y. Huang, S. Wang, X. Cai et al., "Prehypertension and incidence of cardiovascular disease: a meta-analysis," BMC Medicine, vol. 11, article 177, 2013.

[8] F. P. Cappuccio and M. A. Miller, "Cardiovascular disease and hypertension in sub-Saharan Africa: burden, risk and interventions," Internal and Emergency Medicine, vol. 11, no. 3, pp. 299-305, 2016.

[9] P. M. Kearney, M. Whelton, K. Reynolds, P. Muntner, P. K. Whelton, and J. He, "Global burden of hypertension: analysis of worldwide data," The Lancet, vol. 365, no. 9455, pp. 217-223, 2005.

[10] S. S. Lim, T. Vos, and A. D. Flaxman, "A comparative risk assessment of burden of disease and injury attributable to 67 risk factors and risk factor clusters in 21 regions, 1990-2010: a systematic analysis for the Global Burden of Disease Study 2010," The Lancet, vol. 380, no. 9859, pp. 2224-2260, 2013.

[11] B. A. Burket, "Blood pressure survey in two communities in The Volta Region, Ghana, West Africa," Ethnicity \& Disease, vol. 16, pp. 292-294, 2006.

[12] J. Addo, L. Smeeth, and D. A. Leon, "Prevalence, detection, management, and control of hypertension in Ghanaian civil servants," Ethnicity \& Disease, vol. 18, no. 4, pp. 505-511, 2008.

[13] A. G. Hill, R. Darko, J. Seffah, R. M. K. Adanu, J. K. Anarfi, and R. B. Duda, "Health of urban Ghanaian women as identified 
by the Women's Health Study of Accra," International Journal of Gynecology and Obstetrics, vol. 99, no. 2, pp. 150-156, 2007.

[14] W. K. Bosu, "Epidemic of hypertension in Ghana: a systematic review," BMC Public Health, vol. 10, article 418, 2010.

[15] S. H. Nyarko, "Prevalence and sociodemographic determinants of hypertension history among women in reproductive age in Ghana," International Journal of Hypertension, vol. 2016, Article ID 3292938, 6 pages, 2016.

[16] A. V. Chobanian, G. L. Bakris, and H. R. Black, "Seventh report of the Joint National Committee on prevention, detection, evaluation, and treatment of high blood pressure," Hypertension, vol. 42, no. 6, pp. 1206-1252, 2003.

[17] "WHO STEPS surveillance manual: the WHO STEPwise approach to chronic disease risk factor surveillance," 2005, http://www.who.int/chp/steps/en/.

[18] R. A. Adebayo, M. O. Balogun, R. A. Adedoyin, O. A. ObashoroJohn, L. A. Bisiriyu, and O. O. Abiodun, "Prevalence of hypertension in three rural communities of Ife North Local Government Area of Osun State, South West Nigeria," Journal of General Internal Medicine, vol. 6, pp. 863-868, 2013.

[19] J. Mufunda, G. Mebrahtu, A. Usman et al., "The prevalence of hypertension and its relationship with obesity: results from a national blood pressure survey in Eritrea," Journal of Human Hypertension, vol. 20, no. 1, pp. 59-65, 2006.

[20] J. Kishore, N. Gupta, C. Kohli, and N. Kumar, "Prevalence of hypertension and determination of its risk factors in Rural Delhi," International Journal of Hypertension, vol. 2016, Article ID 7962595, 6 pages, 2016.

[21] W. T. Arrey, C. A. Dimala, J. Atashili, J. Mbuagbaw, and G. L. Monekosso, "Hypertension, an emerging problem in rural Cameroon: Prevalence, risk factors, and control," International Journal of Hypertension, vol. 2016, Article ID 5639146, 6 pages, 2016.

[22] X. Dai, S. L. Hummel, J. B. Salazar, G. E. Taffet, S. Zieman, and J. B. Schwartz, "Cardiovascular physiology in the older adults," Journal of Geriatric Cardiology, vol. 12, no. 3, pp. 196-201, 2015.

[23] S. S. Franklin, M. G. Larson, S. A. Khan et al., "Does the relation of blood pressure to coronary heart disease risk change with aging? The Framingham Heart Study," Circulation, vol. 103, no. 9, pp. 1245-1249, 2001.

[24] P. Primatesta and N. R. Poulter, "Improvement in hypertension management in England: results from the Health Survey for England 2003," Journal of Hypertension, vol. 24, no. 6, pp. 11871192, 2006.

[25] K. Acheampong, S. Appiah, D. Baffour-Awuah et al., "Prevalence of hypertension and its association with obesity among women attending valley view university hospital, Accra," International Journal of Health Sciences and Research, vol. 8, no. 1, pp. 155-162, 2018.

[26] B. Setters and H. M. Holmes, "Hypertension in the older adult," Primary Care-Clinics in Office Practice, vol. 44, no. 3, pp. 529539, 2017.

[27] S. Stranges, M. Trevisan, J. M. Dorn, J. Dmochowski, and R. P. Donahue, "Body fat distribution, liver enzymes, and risk of hypertension: Evidence from the Western New York Study," Hypertension, vol. 46, no. 5, pp. 1186-1193, 2005.

[28] S. M. Grundy, "Obesity, metabolic syndrome, and cardiovascular disease," The Journal of Clinical Endocrinology \& Metabolism, vol. 89, no. 6, pp. 2595-2600, 2004.
[29] O. S. Ogah, I. Okpechi, I. I. Chukwuonye et al., "Blood pressure, prevalence of hypertension and hypertension related complications in Nigerian Africans: a review," World Journal of Cardiology, vol. 4, no. 12, pp. 327-340, 2012.

[30] S. Ramirez, D. Enquobahrie, G. Nyadzi et al., "Prevalence and correlates of hypertension in rural Africa," Journal of Human Hypertension, vol. 24, pp. 786-795, 2010.

[31] H. M. Shihab, L. A. Meoni, A. Y. Chu et al., "Body mass index and risk of incident hypertension over the life course: The johns hopkins precursors study," Circulation, vol. 126, no. 25, pp. 2983-2989, 2012.

[32] K. Tibazarwa, L. Ntyintyane, K. Sliwa et al., "A time bomb of cardiovascular risk factors in South Africa: results from the Heart of Soweto Study 'Heart Awareness Days"' International Journal of Cardiology, vol. 132, no. 2, pp. 233-239, 2009.

[33] R. A. Adedoyin, C. E. Mbada, L. A. Bisiriyu, R. A. Adebayo, M. O. Balogun, and A. O. Akintomide, "Relationship of anthropometric indicators with blood pressure levels and the risk of hypertension in Nigerian adults," Journal of General Internal Medicine, vol. 1, pp. 33-40, 2008.

[34] L. Borgi, I. Muraki, A. Satija, W. C. Willett, E. B. Rimm, and J. P. Forman, "Fruit and vegetable consumption and the incidence of hypertension in three prospective cohort studies," Hypertension, vol. 67, no. 2, pp. 288-293, 2016.

[35] P. Mirmiran, N. Noori, M. B. Zavareh, and F. Azizi, "Fruit and vegetable consumption and risk factors for cardiovascular disease," Metabolism - Clinical and Experimental, vol. 58, no. 4, pp. 460-468, 2009.

[36] L. Wu, D. Sun, and Y. He, "Fruit and vegetables consumption and incident hypertension: Dose-response meta-analysis of prospective cohort studies," Journal of Human Hypertension, vol. 30, no. 10, pp. 573-580, 2016.

[37] L. Wang, J. E. Manson, J. M. Gaziano, J. E. Buring, and H. D. Sesso, "Fruit and vegetable intake and the risk of hypertension in middle-aged and older women," American Journal of Hypertension, vol. 25, no. 2, pp. 180-189, 2012.

[38] M. Tsubota-Utsugi, T. Ohkubo, M. Kikuya et al., "High fruit intake is associated with a lower risk of future hypertension determined by home blood pressure measurement: The OHASAMA study," Journal of Human Hypertension, vol. 25, no. 3, pp. 164-171, 2011.

[39] M.-W. Liu, H.-J. Yu, S. Yuan et al., "Association between fruit and vegetable intake and the risk of hypertension among Chinese adults: a longitudinal study," European Journal of Nutrition, vol. 57, no. 7, pp. 2639-2647, 2018.

[40] J. M. Nuñez-Cordoba, A. Alonso, J. J. Beunza, S. Palma, E. Gomez-Gracia, and M. A. Martinez-Gonzalez, "Role of vegetables and fruits in Mediterranean diets to prevent hypertension," European Journal of Clinical Nutrition, vol. 63, no. 5, pp. 605612, 2009.

[41] A. Virdis, C. Giannarelli, M. F. Neves, S. Taddei, and L. Ghiadoni, "Cigarette smoking and hypertension," Current Pharmaceutical Design, vol. 16, no. 23, pp. 2518-2525, 2010.

[42] A. Briasoulis, V. Agarwal, and F. H. Messerli, "Alcohol consumption and the risk of hypertension in men and women: a systematic review and meta-analysis," The Journal of Clinical Hypertension, vol. 14, no. 11, pp. 792-798, 2012.

[43] W. Li, D. Wang, C. Wu, O. Shi, Y. Zhou, and Z. Lu, "The effect of body mass index and physical activity on hypertension among Chinese middle-aged and older population," Scientific Reports, vol. 7, no. 1, p. 10256, 2017. 
[44] K. J. Awosan,, M. T. Ibrahim,, E. Essien,, A. A. Yusuf,, and A. Okolo," "Dietary pattern, lifestyle, nutrition status and prevalence of hypertension among traders in Sokoto Central market, Sokoto, Nigeria," International Journal of Nutrition and Metabolism, vol. 6, no. 1, pp. 9-17, 2014. 


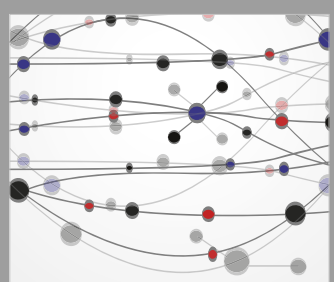

The Scientific World Journal
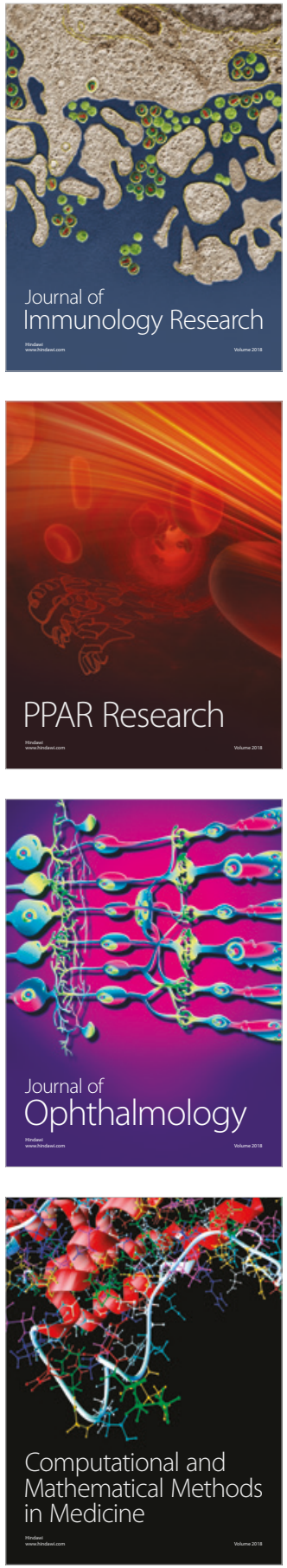

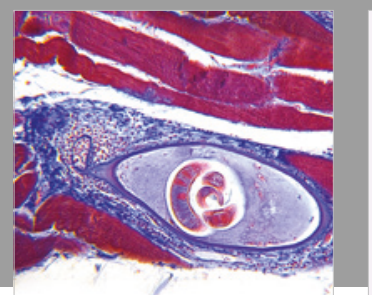

Gastroenterology Research and Practice

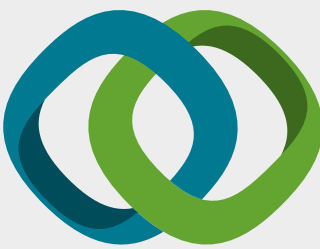

\section{Hindawi}

Submit your manuscripts at

www.hindawi.com
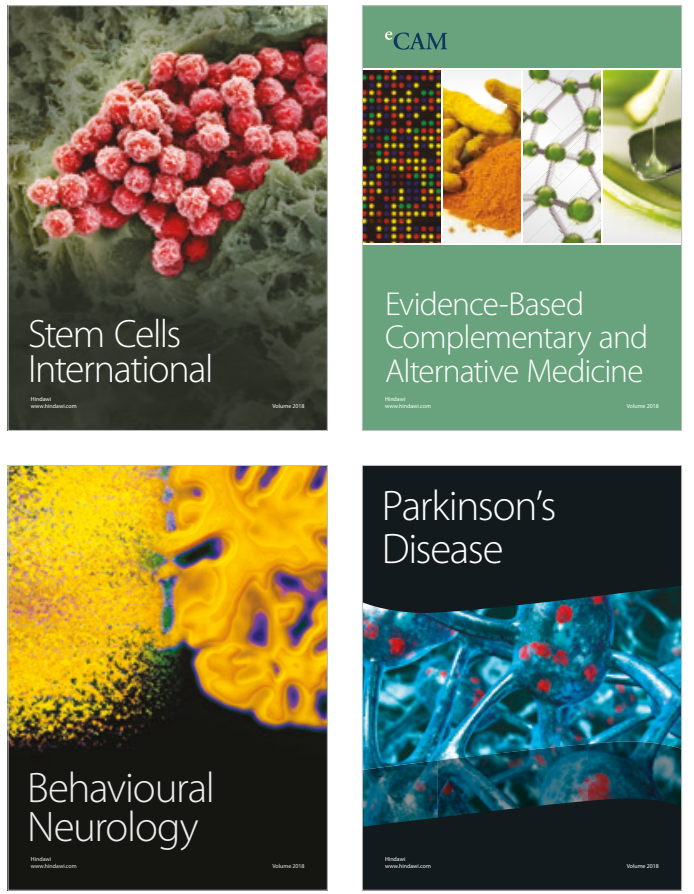

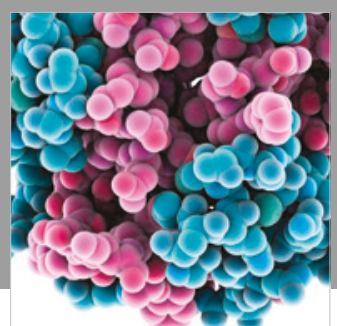

ournal of

Diabetes Research

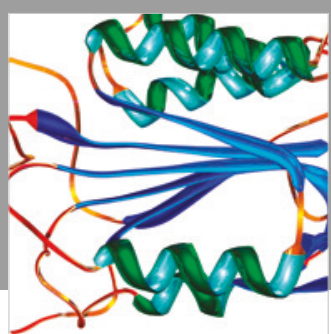

Disease Markers
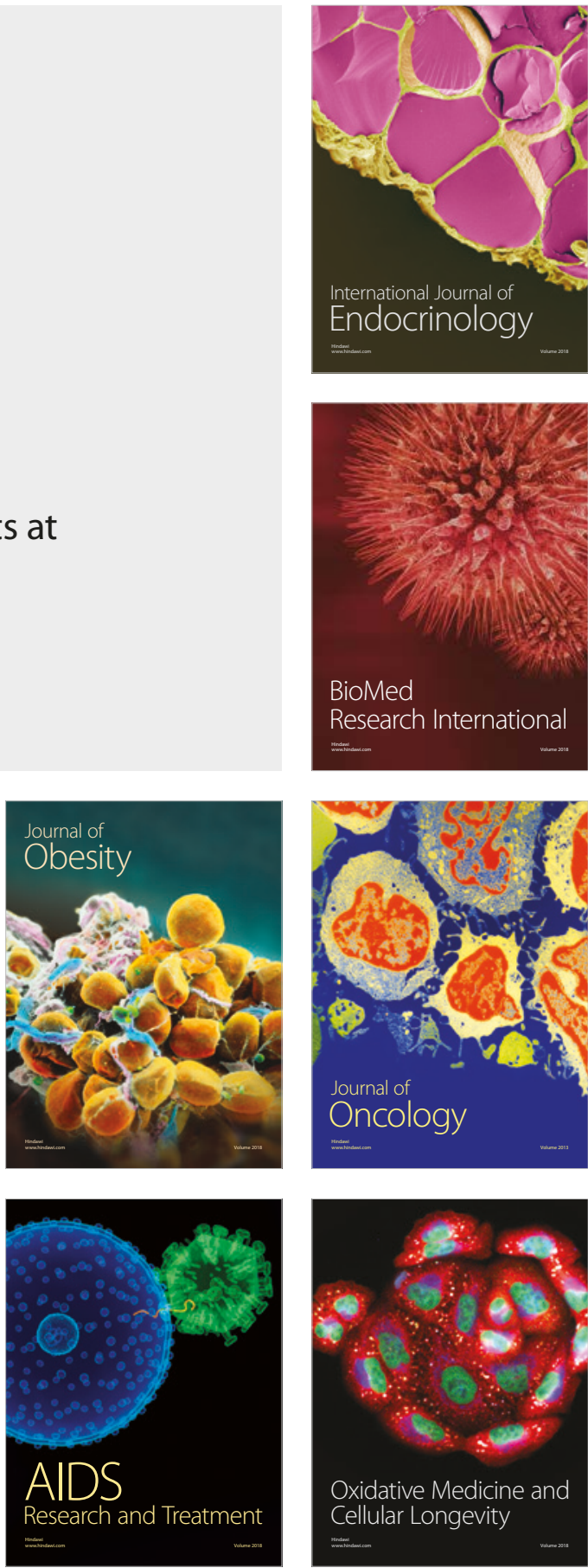